\title{
Anneden-Kıza Kimliğin Yeniden Üretimi: Hiçbir Aşk Hiçbir Ölüm
}

\section{Reproduction of Mother-to-Daughter Identity: Hiçbir Aşk Hiçbir Ölüm}

http://dx.doi.org/10.22559/folklor.2059

Özlem Kanat ${ }^{*}$

Öz

Bu çalışmada İnci Aral'ın Hiçbir Aşk Hiçbir Ölüm adlı romanında anneden-kıza kimliğin yeniden nasıl üretildiği sorusu kadın bakış açısıyla yanıtlanmaya çalışılmıştır. Romanın iki kadın karakteri anne (Sara) ve kızının (Simden) kişilikleri; anne-kız olarak ilişkileri, seçimleri (ya da seçmiş gibi göründükleri) incelenerek toplumsal cinsiyet rollerini de içeren kimliğin yeniden yeniden nasıl üretildiği betimlenmeye çalışılmıştır. Aral, anneyi kızını sürekli eleştiren bir konuma yerleştirirken kızını da annesine benzemekten hep korkan bir konuma yerleştirir. Hiçbir Aşk Hiçbir Ölüm'de birbirine görüntü olarak benzemeyen iki kadının aslında toplumda kabul görme istekleri, eşleri tarafından kabul görme uğruna kendilerini yok sayışları, toplumun idealize ettiği kadına ulaşma çabalarıyla (farklı yolları seçseler de temel amaç aynı olmak üzere) birbirlerine ne kadar benzedikleri, kimliğin bir miras olarak anneden kıza yeniden yeniden nasıl üretildiği görülmüştür. Kadın çalışmaları açısından yazınsal metinler yoluyla deneyim paylaşımı olarak kabul edilebilecek bu çalışma, toplumsal cinsiyet rolleri ve kadının kimlik arayışı açısından farkındalık yaratmayı amaçlamaktadır.

Anahtar sözcükler: Toplumsal cinsiyet, kimlik, kadın romanlarl.

\begin{abstract}
In this study, the question of how mother-to-daughter identity is reproduced in İnci Aral's novel Hiçbir Aşk Hiçbir Ölüm is tried to be answered from a women perspective. The two women characters of the novel are the personalities of mother (Sara) and daughter (Simden); by examining their relationships as mother-daughter and their choices (or what they seem to have chosen), it has been tried to depict how identity, including gender roles, is reproduced again. While Aral places the mother in a position that constantly criticizes her daughter, she places her daughter in a
\end{abstract}

* Dr., Ankara Üniversitesi Eğitim Bilimleri Fakültesi, osoysal@ankara.edu.tr, https:// orcid.org/0000-0002-90712700 
position that is always afraid of resembling her mother. In Hiçbir Aşk Hiçbir Ölüm, it has been seen how similar two women are to each other with their desire to be accepted in society, their ignoring of themselves for the sake of acceptance by their spouses, their efforts to reach the woman idealized by society (the main purpose is the same, even if they choose different paths), how identity is re-produced from mother to daughter as a legacy.This study, which can be regarded as sharing experiences through literary texts in terms of women's studies, aims to raise awareness in terms of gender roles and women's search for identitiy.

Keywords: Gender, identitiy, women literature

\section{Giriş}

Toplumsal cinsiyet (gender) kavramı, cinsiyet (sex) kavramından basit anlamda ayrımı doğuştan getirilen-sonradan kazanılan olarak yapılabilir. Toplumsal cinsiyetin kapsamı, temel değişkenleri, etkileri çeşitli akım ve ideolojilere göre farklılık gösterse de toplumsal cinsiyet rollerinin benimsenmesinde ebeveynlerin rolü bu konuda çalışan bilim insanlarından kabul gören bir gerçektir. Ebeveylerden "anne"nin aile içindeki konumu bir anlamda üretime dayanır: Çocuk dünyaya getirme ve ev işlerini yapan ücretsiz çalışan olma (Walby: 187). Ataerkil bakış açısı kadının varlığını bu üretim ilişkilerine bağlar. Öncelikle geniş ailelerde tanımlanan kadının "biyolojik" ve "emek yoğun" üretim biçimiyle konumlanması, modern yaşamda çekirdek ailelerdeki "ideal" kadın ve erkek rollerini besledi; "uygun" anne modelini de belirledi (Brienes ve Gordon, 1983). Kadının "biyolojik", "emek yoğun" üretimine bir de kariyer baskısı eklendi. Yeni ideal aile "çocuk da yaparım kariyer de" mottosuyla kadından beklenene üçüncü bir boyut daha ekledi. Kadın hem evi için çalışmasına işi için çalışması da eklendi. Kadın sosyal yaşamdan uzak, dinlenmeden ancak evi ve işi için durmadan çalışır duruma geldi (Westwood, 1993). Kariyer baskısı ya da seçimi kadının diğer boyutlarını es geçmesine izin vermeden gerçekleştirebileceği bir varlık alanıydı. Bugün her kesimden kadın seçtikleri ya da bir anlamda mecbur oldukları iş alanlarında var olma baskısını değişik boyutlarda yaşamaktadır. Bazı meslek grupları kadınlar için uzun süredir, uygun görülürken; yöneticilik gibi karar mekanizmasında önemli ölçüde söz sahibi olunan işlere sahip kadınların "erkeklerden" daha iyi olduğunu kanıtlama baskısı meslek yaşamlarının bir parçası haline gelmiştir (O’Connor vd., 2019, Tan, 1994). Kadın açısından temelde her ne işi seçerse seçsin öncelikli görevi aile içindeki rolünün getirdiği sorumluluk ve işlerdir. Eğitimli ya da az eğitimli kadınlardan beklenen eş ve anne rollerini öncelemeleridir. Kadının var olması bir anlamda birine bağımlı olma ya da referans noktası olarak birini alma ile olanaklı hale gelir. Toplumların dokusuna sinen bu kabul, kadını "en bağımsız" olduğunu iddia ettiği anda dahi yakalar. Çünkü toplumsal cinsiyet rolleri ile örülmüş kimlikler yeniden üretim yoluyla nesilden nesile aktarılır, kemikleşinceye değin yerleşir.

İnci Aral, eğitimli, az eğitimli, varlıkl, yoksul, muhafazakâr, açık görüşlü birçok kesimden kadının öyküsüne kitaplarında yer verir. Yazar, öykü ve romanlarında kadına hem toplumsal bir imge hem de bir birey olarak bakar, kurgusuna böyle yansıtır. Kadın ka- 
rakterlerin öne çıktığı bir anlamda "kadın edebiyatı" olarak nitelendirilebilecek öykü ve romanlarında toplumsal konulara kadın bakış açısıyla yaklaşır. Aral'ın kadın odaklı romanları arasında Hiçbir Aşk Hiçbir Ölüm iki kadın karaktere (anne ve kızına) odaklanır; bu bağlamda roman, toplumsal cinsiyet rolleriyle örülen kadın kimliğinin nasıl yaratıldığı ve nasıl yeniden yeniden üretildiği sorusuna yanıt oluşturmak için uygun bir metindir.

\section{Birbirine benzeyenlerin birbirine benzememe çatışması: Sara ve Simden}

İnci Aral'ın Hiçbir Aşk Hiçbir Ölüm 'nde kurgu anne-kı ekseninde gelişir. Simden (Sara'nın kızı), annesinin 3 yaşından terk ettiği ve annesini ancak 13 yaşındayken tanımış bir genç kadındır. Romandaki olay çizgisinde ileri geri gidişlerle okur Simden'in terk edilişine, annesine kavuşmasına(!) tanık olur. Sara (Ailesinin verdiği ad Halise'dir. Sara adını kullanmayı seçer.) ise abisinin menenjitten yitiren, oğlunu kaybedince dünyaya küsen bir annenin kızıdır. Bir anlamda o da Simden gibi çocukken annesi tarafından terk edilmiştir:

\footnotetext{
"Anne ben ne zaman okula gideceğim? Annesi konuşmuyor onunla, görmeden yüzüne bakıyor ve ağlıyor yalnızca. Babaannesi annesinin odasına bırakmıyor onu. Acılı, hasta, diyor. Ağabeyi cennete gitti. Burak ağabeyi menenjit olup uçtu. Önce gözleri kör oldu, sonra gökyüzüne karıştı. Annesi onu istemiyor artık. Burak’ı düşünüyor hep, bir tek onu seviyor. Kızını görmüyor gözleri." (Bölüm 4, s. 9)1
}

Sara'nın annenin gölgesinden uzak babasının soğuk gölgesinde yetişir. Baba vardır ama fiziksel anlamda. Duygusal anlamda anne ile birlikte baba da bir anlamda yok olur. Sara'nın da yok sayıldığı yalnızca fiziksel gereksinimlerin karşılandığı bir evde büyür Sara:

"Radyosuyla birlikte kapandığı odadan aylar boyu çıkmayışı, yitirilmiş bir çocuğun acısıyla, yaşamakta olan çocuğunu da kendinden uzaklaştırması, onu neredeyse yok sayması bağışlanmaz bir bencillik olarak görünüyordu gözüne. Kırgınlığı öfkeye, kızgınlığa varıyordu o zaman. Annesi kendini esirgemişti kızından. ” (Bölüm 4, s. 26)

Sara annesine duyduğu özlem ve sevgi açlığı ona olan öfkeye dönüşür. Sara’nın annesi ise varlığını yalnızca erkek çocuğu üzerinden tanımlamış bir annedir. Sara’nın yok sayılışı onun annesine büyük bir öfke duymasına neden olur. Sara'nın ile kızı arasındaki ilişki de benzer bir biçimde gelişir. Sara cilveli, dış görünüşünü çok önemseyen bir kadın görünümündeyken Simden daha sakin, duygularını belli etmeyen ve görünüş olarak sade bir kadındır. İlk bakışta birbirlerine benzemiyor gibi görünen (ki Simden'in en büyük korkularından biri annesine benzemektir.) anne-kız, annelerine duydukları öfke ve erkeklerin karşısında kendilerini konumlandırışları-algılayışları olarak çok benzerdir.

Sara için içindeki boşluğu giderme, kendini tam hissetme yolu birinin "eşi” olmakla olanaklıydı. Bir şekilde yalnız kaldığında içindeki boşluk duygusu ile başa çıkamamış en yakınındaki eş adayına sarılmıştır. Sara bir anlamda toplumsal normlar gereği yalnız bir kadının toplumda kabul edilmeyeceğinin farkında olduğundan hep "birinin eşi”" ol- 
mayı seçmiştir. Sara aslında, zeki ve birçok yeteneği olan bir kadın olmasına karşın bir anlamda toplumun ondan beklediği gibi "kabul" etmeyi, "boyun eğmeyi" seçmiştir aksi gibi davranıyor görünse de sonuç bağımlılığa çıkmaktadır:

“İlk kocasından ayrılıp İstanbul’a geldiğinde bu otellerden birinde kalmıştı kısa bir süre. O günlerde öyle çaresiz bir boşluk duygusu içindeydi ki düşündüğünde şimdi bile anlatılmaz bir yorgunluk çöküyordu üstüne. Kendine duyduğu inancı, güveni tümüyle yitirmişti. Benliği paramparçaydı. Kadınların vazgeçemedikleri düzen tutkusundan, bir erkeğe bağlanma saplantı ve iyimserliğinden, boşanmış olmasına karşın kurtulamamıştı henüz.” (Bölüm 2, s. 2-3)

Sara'nın düzen bağımlılığı ve bir erkeğe bağlanma saplantısı Simden'le olan ilişkilerinde de öfke kaynaklarından biridir. Simden annesinin düzen saplantısına tanık olduğu anlarda büyük bir kızgınlık ve kırgınlık duyar:

“Asıl neden büyük olasılıkla, kendisinin, onun planladığı ve istediği gibi öğle yemeğine değil akşam çayına gelmiş olmasıydı. Çevresindeki her şeyi, herkesi kendi tasarım ve düzeni içine sokmak, yönlendirmek isteği en belirgin davranış özelliğiydi çünkü. $\mathrm{O}$ akşamüstü de mirası ile ilgili garip, yersiz şeyler söylemiş, her zamanki gibi hiç yoktan tartışmışlardı. Sonunda Simden, sinirlenmiş, dayanılmaz birisin anne, demişti. Ona yüz yüze oldukları zamanlar anne derdi yalnızca. Arkasından, yanında değilken babaannesi ve başkaları gibi Sara olarak anardı." (Bölüm 1, s. 25).

Simden'in annesinde görmeye dayanamadığı bağımlılıklar Simden'i de kuşatır. Tıp doktoru olan Simden mesleğini, eşinin de yönlendirmesiyle "gece nöbetleri" gibi konformist nedenlerle bırakmıştır. Eşinin çok para kazandığı için Simden'in mesleğine hobi gözüyle bakar, Simden de eşinin isteklerine uygun olarak bir hobi seçer, evinde bir seramik atölyesi kurar. Yıllar sonra eşi onu aldattı̆̆ında, hatta aldatmadan önce ilişkileri bittiğinde eşinden ayrılamaz, tıpkı annesi gibi düzenini bırakmak, yıllarca eşine göre şekillendirdiği kişiliğini kendini terk etmek, değişmek istemez:

"Bu yüzden değildi. Yeni yaşamı o kadar hareketli ve yoğundu ki çok zorlanıyordu. Hastanede neredeyse üç günde bir gece nöbeti tutmak zorunda kalmıştı. Uykusuz ameliyatlara girmiş, sinirleri bozulmuştu. Sinavlara yeterince hazırlanamamış, başarısız olmuştu. Bütün bunlar yoluna girebilirdi kuşkusuz, ama hiç destek görmemişti Ömer'den. Mesleğine, bağımsızlığına saygı göstermemişti o. Yeterince isteseydin yapardın kızım, diyordu. Kolayına geldi bıraktın. Ömer daha düz, daha pratik biri, diye düşünürdü. Kendisi karmaşıtı ona göre; daha zor, duygusal ve kendine güvensiz. Var olan çözümleri bile çözümsüz hale getirebilme yetisi vardı sanki Simden'de. Ömer'in sözüydü bu, ama doğruydu." (Bölüm 1, s. 12)

Simden eşinin (Ömer'in) ona uygun gördüğü mesleği, yaşam biçimini bir anlamda kişiliği kabul eder. Bu kabul ediş toplumsal normlara uygun olarak "uysallık ve ağırbaşl1lıkla" biçimlenir. Simden aslında gerçekte "Ne istiyorum?" sorusunu sormadan kabul edilme-onaylanma ve bir düzen uğruna kendini yok saymıştır (tıpkı annesi gibi)."Dinginliğe, kusursuz görünmeye ödediği bedel içini kurutmuş, ruhunu törpülemişti.” (Bölüm 1, s.14) 
Anne-kızın olayları kabul ediş şekilleri bile gerçekte hissettikleri değil, var olan düzeni-toplumdaki statülerini ve onaylanan eş olma konumunu koruma üzerinedir. Simden eşinin onu aldattığını öğrendiğinde bile "anlayışl1-kontrollü” tavrını korur, eşinin dayattığı düşünceleri kendi düşünceleri gibi kabul eder.:

"Gelip geçici bir olaydı tatlım, öylesine bir şeydi. Kıskançlık krizleri yaratmadığın, düşmanlık gütmediğin için teşekkür ederim. Her şey yoluna girecek inan. Gösterdiğin sabır ve anlayış çok değerli benim için, diyordu Ömer.” (Bölüm 1, s. 31)

"Düşüncelerini, eylemini, mantıklı açıklamalarla bana dayatmada üstüne yoktur onun, diye düşündü, sinirlenerek.” (Bölüm 1, s.3)

Sara'nın yaşamda var olma biçimi birinin eşi olma iken, Simden’i yaşamına tekrar çok geç kalarak alması ve çocuk yaşta onu bırakması da bu nedenledir. Çocuklu bir kadını erkelerin istemeyeceği düşüncesidir. Bu noktada Aral, toplumsalda kabul gören kadın-eş rollerine dönük okura bir soru işareti bırakır: Kadınları toplum "iyi yürekliler ve kötü yürekliler" olarak değil kadın kimliğinin ataerkil toplumda kabul gördüğü biçimde sinıflar. Aral'ın romanda anneden-kıza yeniden yeniden üretilen toplumsal cinsiyet rollerini yaratmada erkelerin rollerini gözler önüne sererken romanda en büyük eleştiri kadınlara dönüktür. Kadınlar romanda ataerkil toplumun onayladığı toplumsal cinsiyet rollerini beklendiği şekilde kabul edenler hem de bu rollerin yeniden yeniden üretilmesi konusunda uygun zemini hazırlayanlar olarak eleştirilir. Yazar bu eleştiriyi, başlarda "ideal eşler" topluluğuna katılmakta güçlük yaşayan Simden'in gözüyle okura sunar, Simden “aşırı bakımlı” bir eş olmaktan hoşlanmaz ama oturdukları semtteki kadınlardan aslında farklıdır:

"Onlardan olamadığını ve olamayacağını ilk günden anlamışlardı zaten. Kil yo-
ğuran ellerinin bakımsızlığını, saçlarının kendi haline bırakılmışlığını, giyiminin
sadeliğini ve konuşmasının doğallığını yadırgamışlardı. Simden hep garip, rahat-
sızlık verici bir güvensizlik duygusuna kapılmıştı o insanlarla; özellikle kadınlarla
birlikte olduğunda. Kişiliği geçici olarak yok edilmiş, ortadan kaldırılmış ve hepsi
birbirine benzeyen bütün ötekilere benzemekle cezalandırılmış gibi geliyordu ona.
Zaman öyle amaçsız, öyle boş, öyle ağır ve sıkıcı geçiyordu ki onlarla.” (Bölüm
1, s. 6)

Simden'in annesi Sara kızının tam tersi çok bakımlı bir kadındır. Sara ise "kabul" edilmenin yolunu görünümüyle kusursuz kadın olma yoluyla gerçekleştirmeye çalışmıştır. Simden de Sara da kabul görmenin yolunu bir biçimde toplumun ön gördüğü ideal kadın ve eş olma yoluyla gerçekleştirir:

“İkiyüzlü davranmıştı ona belki başından beri. Uysallıkla, teslim olmayı seçerek, kendi kişiliğini geriye çekip onun önünü boşaltarak sürdürmüştü evliliğini. Ne kadar kızarsa kızsın, yüz yüze olduklarında nasıl olduğunu bilmeden sürekli uzlaşıyordu onunla. Tartışmayı kendisi çıkardığı zaman bile yenilmeyi yeğliyordu. Bir de bakıyordu ki bir noktadan sonra alttan almaya başlamış. Sonuna kadar gitmekten, haklı çıkmaktan korkuyormuş gibi.” (Bölüm 1, s.11) 


\section{Sonuç}

Toplumsal cinsiyet rollerinin mevcut biçimiyle varlığını sürdürme nedenlerinden biri yeniden üretilmesidir. Bu bağlamda anne-kız ilişkisi ve birey olarak kendilerini tanımlama biçimleri toplumsal cinsiyet rollerinin yeniden üretilmesinde önemli rol oynar. İnci Aral'ın kadın bakış açısıyla yazılmış Hiçbir Aşk Hiçbir Ölüm romanında bu ilişki anne-kız ilişkisi örgüsünde ortaya koyulur ve eleştirilir. Aral, Sara ve Simden'i toplumsal normların nasıl kuşattığını, kimliklerini toplumsal normların kuşatmasıyla anneden kıza aktarılan bir benimsemeyle nasıl yok saydıklarını; mevcut kimliklerinin ve benimsedikleri rollerin büyük ölçüde kendilerine ait olmadığını gözler önüne serer. Kadın çalışmalarında deneyim paylaşımı önemli bir yer tutar; bu bağlamda Aral'ın Hiçbir Aşk Hiçbir Ölüm'ü kadının toplumdaki konumu, kişiliğinin üretimi, anneden kıza kimliğin aktarımı konusunda deneyim paylaşımı niteliğindir. Edebiyatın deneyim paylaşımı boyutunun okur açısından ne denli etkili olduğu düşünürse (estetik değer taşıdığı için), romanlar yoluyla deneyim aktarımının farkındalık yaratmadaki olası etkisi anlaşılabilir. Aral'ın da romanı anneden kıza kimliğin nasıl aktarıldığı konusundaki farkındalığı kadın bakış açısıyla yaratır.

\section{Notlar}

1 Bu makale için romanın e-kitap biçimi yeğlendiği için e-kitap bölümlemesine uygun olarak romandan alıntılarda sayfa numarası bölüm numarası ile birlikte verilmiştir.

\section{Kaynakça}

Brienes, W \& Gordon, L. (1983). The new scholarship on Family violence. Sings: Journal of Women in Culture and Society, (8), 490-531.

O’Connor, P., Martin, P. Y., Carvalho, T., Hagan, C. O., Veronesi, L., Mich, O., Saglamer, G., Tan, M. G., \& Caglayan, H. (2019). Leadership practices by senior position holders in Higher Educational Research Institutes: Stealth power in action? Leadership, 15(6), 722-743. https://doi. org/10.1177/1742715019853200

Tan, M . (1994). Toplumsal değişim ve eğitim: Kadın bakış açısından. Ankara University Journal of Faculty of Educational Sciences (JFES) , 27 (1) , 83-96 . doi: 10.1501/Egifak_0000000438

Walby, S. (1993). The elements of the patriarchal mode of production. Women Studies: Essential Readings (Ed. S. Falkuner\& S. Jackson), 187-188. New York University.

Westwood, S. (1993) Domestic labourers, or stand by man-while he was sit down and has a cup of tea. Women Studies: Essential Readings (Ed. S. Falkuner\& S. Jackson), 181-184. New York University. 